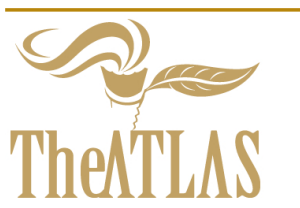

\title{
Engineering Transdisciplinarity in University Academic Affairs: Challenges, Dilemmas, and Progress
}

\author{
Eunsook Hyun, University of Massachusetts Boston, USA, Email: Eunsook.Hyun@umb.edu
}

doi: $10.22545 / 2012 / 00027$

$S^{2}$ ince the 1970s the notion of transdisciplinarity and pragmatic approaches to it have challenged the monolithic traditional orientation and procedures of academia. The long tradition of monodisciplinary academic departmentalization in higher education institutions has crippled the development of human knowledge, way of doing, and even world view; ironically, it has hindered understanding of the interconnected and interdependent ecological human and natural world. Monodisciplinary academic departmentalization has perpetually and inherently limited the discovery of knowledge and its application to complex real-life problems that demand solutions to assure a sustainable and democratic human society. This article presents a discussion of strategic engineering in higher education academic affairs aiming toward transdisciplinary teaching, learning, research, service, and curriculum transformation with emphasis on challenges, dilemmas, and progress.

Keywords: transdisciplinarity (TD), higher education, academic affairs, higher education curriculum.

\section{Introduction}

"The world has problems, but universities have departments" (Brewer, [1])

\begin{abstract}
"Do you replicate what exists, or do you design what you really need?" (Michael Crow, ASU president, 2002, Inaugural address)
\end{abstract}

The basic infrastructure of U.S. contemporary higher education institutions is based on the three pillars: academic affairs, administrative affairs, and student affairs. Among them, academic affairs, encompassing faculty, students, teaching, learning, research, services, and curriculum, is the essential element of a university; and it reflects the social responsibility of the university as the educational agency for the human community. In the $21^{\text {st }}$ century, U.S. higher education institutions face a very different kind of challenge compared to the governmental engineering of geopolitical and geohistorical expectations of the educational responsibilities of universities in previous centuries (e.g., The Morrill Act of 1862; Servicemembers' Readjustment Act of 1944; Civil Rights Movement of the 1960s; The Test of Leadership: Charting the Future of U. S. Higher Education, a 2006 report by the U. S. Department of Education [2] ) (further discussion see elsewhere, Hyun, $[3,4])$.

As a result of globalization, emergent problems of human society have become increasingly complex, interconnected, and interdependent in nonlin- 
ear modes (e.g., global public health, financial crisis, climate change, public education, etc.). These kinds of problems are neither confined to particular sectors or disciplines nor easily predictable. Human beings face nonlinear dynamics, uncertainties, and high geopolitical stakes in decision making, coupled with ethical dilemmas and complexity. As legitimized social agencies, higher education institutions have a major role to play in preparing the kind of well-educated, critical, knowledgeable, and flexible workforce necessary to contemporary and futuristic economic, social, transnational, and transcultural endeavors in the complex and diverse global human society.

In the 1970s and again in the 1990s, the focus was on challenging unrealistic and ineffective higher education teaching, learning, research, and curriculum that systematically lacked the full integration of disciplines necessary to understand and solve real complex human problems. Researchers have discussed how mono-, inter-, or multidisciplinary curriculum has led to limited capacities in preparing new workforces to deal with multiple layers of complex human problems in the current transnational and transcultural human society. Teaching, learning, research activities, service engagement, and degree programs and curricula in higher education have clearly revealed a need to transform beyond the monodisciplinary, transgressing disciplinary boundaries and leading toward transdisciplinary, borderless engagement (e.g., Darbellay, Cockell, Billotte, \& Waldvogel, [5]; Hadorn, Bradley, Pohl, Rist, \& Wisemann, [6] Hammer \& Söderqvist, [7]; Hyun, [4]; Jantsch, [8] Kaufman, Moss, \& Osborn, [9]; Kessel \& Rosenfield, [10]; Klein, [11]; Klein, Grossenbacher-Mansuy, Häberli, Bill, Scholz, \& Welti, [12]; Lawrence, [13]; Kötter \& Balsiger, [14]; Max-Neef, [15]; McWilliam, Hearn, \& Haseman, [16]; Mroczkowski, [17]; Nicolescu, [18,19,20,21,22]; Piaget, [23]; Pohl, [24]; Ramadier, [25]; Wickson, Carew, \& Russell, [26]).

In the $21^{\text {st }}$ century, discourse on change in higher education curriculum has moved from the monodisciplinary to the interdisciplinary, multidisciplinary, and transdisciplinary, reflecting an emerging understanding of the complex social ecology of the changing human world. A means to increasing integrated knowledge and practice without disciplinary boundaries, transdisciplinarity may ultimately provide an avenue for engagement that promotes full understanding of and problem-solving capacity directed at complex human problems that are no longer merely local issues but globally connected transnational matters. Transdisciplinarity is a democratic epistemology and action that challenges all of us in academia, industry, government, and various human organizations, both public and private, the basis of whose operation comprises all forms of existing disciplinary human knowledge, science, and technology (Hyun, in press). The essential purposes of transdisciplinarity are (a) to signify and to engage in a unity of knowledge and surpass mono-, inter-, and multidisciplinary approaches and (b) to build a capacity for human knowledge that is responsive to solve problems affecting real lives. Transdisciplinarity inspires us to ponder a unity of knowledge beyond traditionally accepted disciplines (Nicolescu, $[20])$.

Jean Piaget, a French-speaking Swiss developmental psychologist known for his theory of cognitive development and epistemological studies (generic epistemology) with children, introduced the term transdisciplinarity in 1970. Throughout his life, Piaget [23] argued that education is the only means to saving human societies from collapse, regardless of whether cataclysmic or gradual. A question, however, remains: What kinds of education might be introduced to learners, researchers, policy makers, and various practitioners that would lead to a unity of human knowledge capacity, practice, potentiality, and awareness beyond the disciplinary boundaries? To uncover the nature and characteristics of the flow of information circulating among the various branches of knowledge, to develop research in a new scientific transdisciplinary mode, and to create a global competence yielding educational capacity (deeducate, re-educate, and newly educate) in borderless disciplines-these are the goals of the university, the agent of higher education institution. One of the most critical and fundamental responsibilities of the university is to lead this transformation. The most legitimized social agent, creating, discovering, conveying, disputing, accepting, and disseminating various forms of epistemology and its agreement process, the university, an institutional organization, is a cultural artifact (Hyun, [3]). Among the most traditional of all institutions, it has been known as the one most responsible for changes in human history (Seymour, [27]). With this critical awareness of the role and responsibility of contemporary higher education, in this paper I share how one public research univer- 
sity has made a strategic effort in academic affairs in building a transdisciplinary capacity for teaching, learning, research, service, and curriculum transformation, coupled with transnational and transcultural endeavors. The paper was originally presented at the ATLAS's Transdisciplinary, Transnational and Transcultural Biennial Conference, June, 2012, Taichung, Taiwan.

\section{Academic Affairs' Strategic Approaches}

\subsection{Basic Guiding Principle}

Transdisciplinarity does not entail new disciplinary knowledge; instead it involves an inherent and perpetual capacity of simultaneously deepening and extending disciplinary approaches for the improvement of borderless human knowledge and engagement. It inspires or triggers the emergence of new or different information and interactions derived from encounters among various disciplines and leads to new and different possibilities of understanding nature and engaging with reality. Transdisciplinarity does not require mastery of disciplines, but it motivates individuals to work toward openness by dialoguing, sharing, connecting, fusing, and surpassing existing disciplinary boundaries. In this borderless process, "no single culture is privileged over any other culture. The transdisciplinary approach is inherently transcultural' (as indicated in the Article 10 of the International Center for Transdisciplinary Research (CIRET, [28]), founded in 1987). Basarab Nicolescu [29] claimed that only the transdisciplinary approach can effectively reconcile the challenges of the 21st century. He further argued, "Universal sharing of knowledge cannot take place without the emergence of a new tolerance founded on the transdisciplinary attitude," suggesting the necessity of putting transcultural, trans-religious, transpolitical, and transnational visions into transdisciplinary practice (p.1). The notion of Transdisciplinarity and its organic practice cannot be separated from Transcultural and Transnational engagement, and that, the triple $\mathrm{T}$ (TTT), has been my basic guiding principle in leading and facilitating inter- and transnational endeavors for faculty, students, staff, academic units, and centers and institutes at the University of Massachusetts Boston (UMass Boston).

\subsection{Institutional Background}

UMass Boston devotes a high proportion of research and public service activities to the cultural, social, and economic development of the state. It is nationally recognized as a model of excellence for urban universities (one of the top 20 urban universities in the country). A comprehensive, doctorate-granting campus, the university provides challenging teaching, distinguished research, and extensive service that particularly respond to the academic and economic needs in urban areas in the state and their diverse populations. The six core concepts of the mission of the institutions are access, excellence, public service, innovation, economic development, and quality of life. With a growing reputation for innovative research addressing complex urban issues, the university, founded in 1964, is the only public research university in the metropolitan area, offering its diverse student population both an intimate learning environment and the rich experience of a well-known North American city. As of fall 2012, its nine colleges and graduate schools have served over 900 faculty members and more than 16,000 students at the baccalaureate (97 degree programs), master's (45 different degree programs and 16 tracks), and doctoral (more than 35 different degree programs including tracks) levels as well as 37 graduate certificates, including Certificate of Advanced Graduate Studies (CAGS), while engaging local, national, and international constituents through academic programs, research centers, and public service activities. The university, proudly hailing itself as "a research university with a teaching soul," has been increasingly recognized as a national model of excellence for urban universities.

At this nearly a half-century-old higher education institution, no strategic effort at UMass Boston had promoted a transdisciplinary emphasis in academic affairs for faculty and students for their research, teaching, learning, curriculum transformation, and professional development until AY 2008-2009, when the current academic affairs administrative leadership designated internationalization a strategic effort. Thus, a new associate provost position was created along with a new academic affairs office, the Office of Inter-/Transnational Affairs (OITA). With my scholarship in higher education curriculum along with administrative leadership experience in the internationalization of academic affairs, I was appointed associate provost and head of OITA. Since then, I 
have led the University in strategic planning and development and played a significant role in internationally focused academic and research programs based on transdisciplinary, transnational, and transcultural academic affairs, for example: increasing the strategic capacities of research and study-abroad academic programs for both students and faculty; streamlining administrative processes to enrich the TTT elements of teaching, curriculum, research, and community engagement; facilitating hiring, mentoring, and assessing faculty in light of TTT teaching, research, service, and curriculum transformation; building and enhancing international partnerships for TTT aim and scope in conjunction with academic units and programs; developing and providing funding programs and support for faculty, students, academic units, and professional staff for their TTT teaching, research, learning, and service engagement in local, national, and global contexts, etc.

\subsection{Reframing Academic Affairs in Motion}

The mission of OITA at UMass Boston is to facilitate the processes necessary for strategically integrating international (global), transnational (borderless), transcultural and national trends and policies into the transdisciplinary curriculum, teaching, learning, research, community engagement, and service functions of the university. The objectives of OITA are as follows:

- To promote involvement of all students in significant international educational experiences in the context of global-urban communities;

- To create and maintain a stimulating and supportive academic and cultural environment for and with students and scholars;

- To support transnational academic curricula that are transdisciplinary and trans-collegiate;

- To promote and enhance faculty's teaching, research, and multiple forms of scholarship activities pertaining to global-urban matters and applying transdisciplinary approaches; and

- To ensure efficient and coherent coordination for campus-wide transdisciplinary, transnational, and transcultural (TTT) academic affairs.

In the U.S. higher education setting, a transformative strategic evolution can take place neither explicitly nor implicitly without considering at least four domains-structural leadership, political leadership, symbolic leadership, and human resource management (e.g., Bolman \& Gallos, [30)-especially if the strategic effort is to be collectively meaningful, thus leading to a lived experience with sustainable impact. The four domains were considered as part of the process of reframing academic affairs and putting the TTT strategic effort into practice, as shown below (see Figure 1):

- Structural change and enhancement: creating a new associate provost position with responsibilities as an executive leader charged with building institutional accountability and transparency in establishing strategic, inclusive, and systematic communication and engagement in TTT academic affairs.

- Political inclusiveness: promoting, valuing, and acknowledging TTT activities as essential elements in cross-disciplinary transcultural academic engagement on campus among executive leaders (e.g., deans), mid-level leaders (e.g., chairs and directors), and faculty.

- Support of human resources and articulation of collaborative strategies: facilitating the alignment of individual and organizational needs as a critical element of TTT, such as new faculty lines, joint appointments, joint tenure and promotion $(\mathrm{T} \& \mathrm{P})$ review process, faculty cross-departmental socialization and mentoring to nurture TTT culture, etc.

- Symbolic shared vision: making TTT efforts publicly visible in the strategic mission of the university in conjunction with building its capacity as the "Research University With a Teaching Soul," that is, our contemporary aim and future responsibility for the community we serve.

Traditional departmentalization in academia has been a fundamental, perpetual, and inherent block to imagining transdisciplinarity. In terms of academicunit and departmental-level TTT engagement, however, I have always reminded myself that "we have to work with what we've got." The pros and cons of individual unit-based academic affairs considered, three approaches to TTT have been utilized as follows:

At the individual faculty level: 


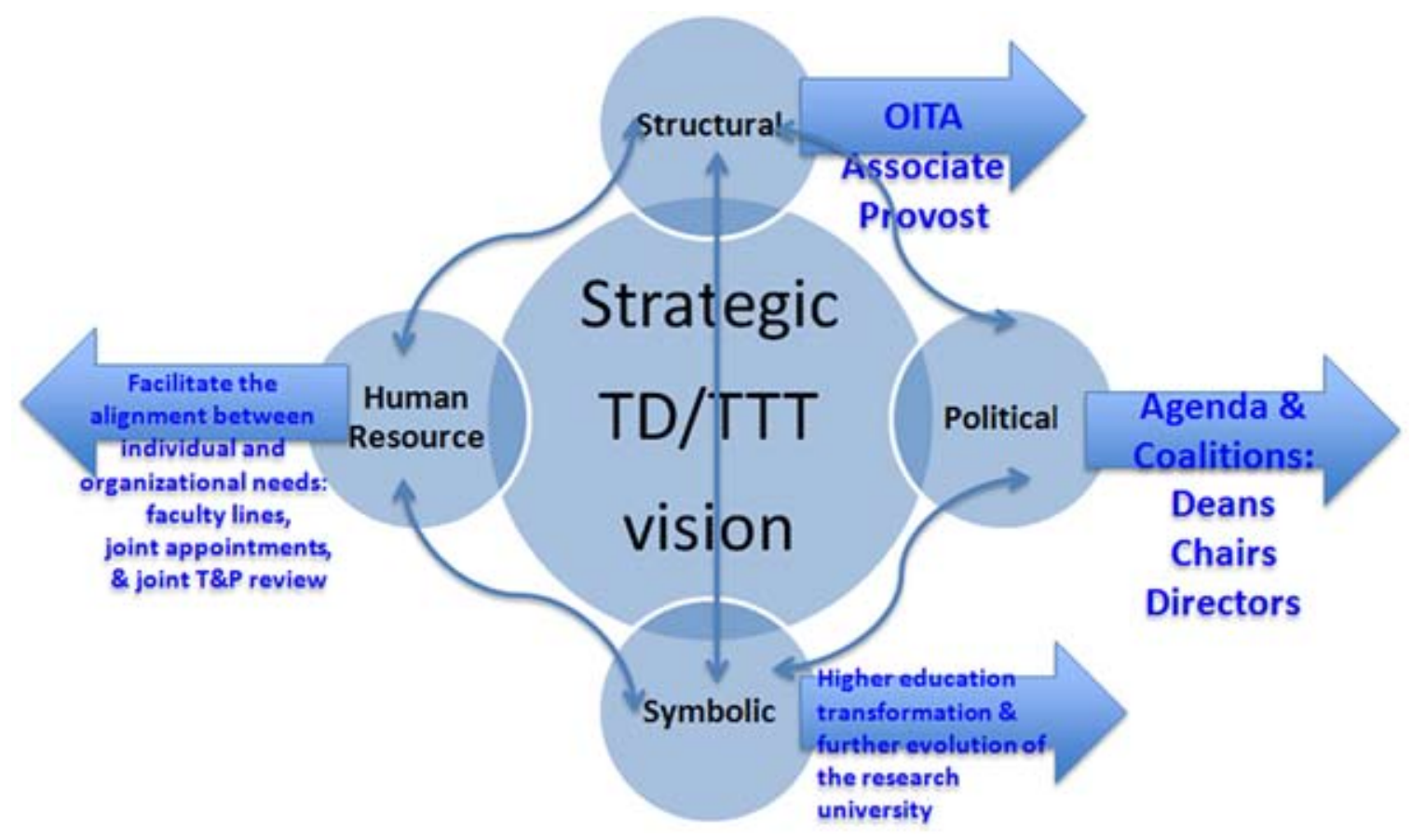

Figure 1: Reframing academic affairs in motion.

- Facilitating individual faculty members' imagination of the transdisciplinary teaching approach (e.g., by providing pragmatic tips for the development of transdisciplinary course syllabi in conjunction with using library resources and connecting with faculty from other academic departments teaching related courses)

- Facilitating faculty cross-border matchmaking for a transdisciplinary research project initiative and course/syllabus development

- Facilitating library support (VERY CRITICAL) in collaboration with library personnel (e.g., helping faculty to look for transdisciplinary materials, to build transdisciplinary online course resources, etc.)

- Developing, providing, and facilitating a formal Faculty Research/Study Abroad Program for TTT engagement in a global context

- Developing and providing various funding programs for TTT teaching, research, and service engagement with students in the global-urban community context for service learning-oriented problem-solving initiatives

\section{At the department/program level:}

- Facilitating department chairs' and college deans' cross-border matchmaking for development of new transdisciplinary Ph.D. programs

- Facilitating strategic committee selection from various disciplines, departments, and academic units

- Facilitating joint appointments, contracts, and $\mathrm{T} \& \mathrm{P}$ review processes

- Developing and providing various international funding programs for the infusion of TTT into the unit- and program-level curriculum

\section{At the college level:}

- Facilitating college deans' cross-border interaction for the creation of new transdisciplinary academic units, centers and institutes

- Facilitating college deans in strategic inclusive cross-border committee selection from various disciplines for new academic initiatives

- Facilitating college deans' in articulation and agreement in joint appointments, contracts, and $\mathrm{T} \& \mathrm{P}$ review processes

- Providing support and incentives at the college level for TTT initiatives 


\subsection{Outcomes and Progresses}

Now, after four years and heading into the fifth year, the campus has begun a culture of imagination that allows faculty members, department chairs, and academic deans to experiment with transdisciplinary initiatives among themselves and with students and various community partners, for example:

- In collaboration with the College of Management, College of Liberal Arts, the College of Science and Mathematics, and the McCormack Graduate School of Policy and Global Studies, creating and offering new Ph.D. programs: first, Global Governances and Human Security with several international partners (Ethiopia, Brazil, etc.); second, a new business management Ph.D. program with a track for Organizations and Social Change (UK, Israel, China, etc.); third, in collaboration with the College of Liberal Arts, College of Nursing and Health Sciences and the McCormack Graduate School of Policy and Global Studies creating and offering a new sociology Ph.D. program with a track for Medical Sociology with several international partners (e.g., the Hannover Medical School and the International Academy of Life Science, Germany) and local hospitals, government organizations, and community health NGOs, to promote research initiatives that offer opportunities for real-life based problem solving in conjunction with public and global health and public policy issues for dealing with health disparity and social justice issues, etc.

- Creating a new transdisciplinary academic unit, the School for the Environment: In the final proposal for the development of the new school, the key orientation of the school was discussed, articulated by a transdisciplinary team of faculty from various academic units:

$\triangleright$ No longer can the environmental disciplines of policy, economics, and business be separated from the environmental sciences; furthermore, the metadiscipline of environmental science has reached a critical nexus, requiring universities to rethink how they teach students and train future leaders. Environmental problems do not recognize national borders; neither can environment training and research be limited by disciplinary borders. $\triangleright$ Many of the benefits provided by the School intentionally blur the lines among teaching, research, and service, ensuring that the School capitalizes on opportunities provided by transdisciplinary collaboration.

$\triangleright$ We will create and strengthen transdisciplinary undergraduate and graduate programs through the development of a transdisciplinary Ph.D. program and combine B.S. or B.A. and M.S. programs. We will foster opportunities for faculty to work across units and expand opportunities for new faculty through joint hires.

$\triangleright$ We envision the School strongly supporting research and doctoral education through the creation of research clusters and dedicated research assistantships and postdoctoral fellowships supporting a broad range of transdisciplinary research across the University.

$\triangleright$ In partnership with governmental and nongovernmental organizations, industry, and communities around the world, we are committed to creating future leaders, immersed in transdisciplinary thinking and focused on developing sustainable solutions to the critical challenges facing our environment.

- Developing and implementing strategic funding programs for faculty, students, staff, academic units, and centers and institutes for TTT-related teaching, research, service, and curriculum initiatives (see http://www.umb.edu/academics/oita/ oita_funding_programs_for_faculty_students_ and_staff ). As of AY 2011-2012, the University had a total 13 different funding programs to support faculty, students, and professional staff for their international teaching, research, learning, and professional development opportunities. In addition, separate funding supports academic units (colleges, research centers, and institutes) for their strategic TTT initiatives.

Because the budget issue is always a challenging matter, a new resource-generating program initiative has been proposed and in place since 2009: the International Visiting Scholar Academy (IVSA) program (http://www.umb.edu/academics/oita/visiting- 
scholars ) designed for international scholars (professors, researchers, and postdoctoral students) from various disciplines who are interested in coming to the University to participate in a series of transdisciplinary professional development workshops with UMass Boston faculty and for their continuous improvement in teaching, research, and services related to their field. The IVSA program was strategically developed to build a culture on the campus among faculty and graduate students to experiment with transdisciplinary ideas with the guests (faculty from other countries with various academic and cultural orientations). It has also created a public comfort zone on campus and a willingness among our faculty, doctoral students, and local community members, in exploring and articulating their research and teaching in a transdisciplinary mode-a new intellectual imagination and possibility to advance academia that is much needed.

\section{Challenges and Dilemmas}

The progress made to date has been somewhat modest, but both concrete and organic. Meaningful and sustainable outcomes require long-term and strategic commitments, which continue to evolve because the core of this type of engineering of academic affairs depends upon collective human history and its dynamics that is always in motion with some degree of human unpredictability. A collectively real and sustainable engagement occurs at the academic-unit level only if both the visible and invisible cultures that constitute the unit have been nurtured collectively by the university mission and history.

A perpetual conflict, however, exists between the institution's historical identity as a commuter urban - public research university serving local and regional communities and the new strategic emphasis on transdisciplinary internationalization of academic affairs; hence, a double layer of challenges and dilemmas has fraught transformative academic engineering at this institution. The response of a typical skeptic may raise the following issues:

Why should a public commuter university be internationalized, not to mention the complexity of understanding what transdisciplinarity is really about and how to implement it? I get the idea of TTT, how the three aspects are interconnected. It sounds logical and scholarly, and I appreciate the notion very much; but is this transdisciplinary approach really possible? To date, most of us, literally everyone was hired by single department; and for a faculty member to fulfill the department's expectation in order for him or her to be retained, he or she must be successful within the department. Historically, many faculty members who have done interdisciplinary teaching and research have had difficulty earning a successful T\&P review on this campus, even at the fourth-year review.

The foregoing is the product of innocent pondering with a historical memory, a response typically voiced by many faculty and staff members and administrators alike, all of whom were born, raised, and educated, have lived in the same city, and have worked at this university most of their professional lives. At this university, many individuals who belong to this "group," and they have a profound connection with the university and the community about which they care deeply.

A well-respected senior faculty member, who has been teaching at this university since 1965, said:

This is a well-known commuter institution. We do not need to spend money to send faculty overseas to do TTT research. We'd better use that money for local students, providing more scholarship opportunities for them to come to the university for their college education. Besides this city is already international, and some of us are already doing interdisciplinary work. More and more are moving in this direction! We have served transnational and transcultural students since the beginning of this university's history! It is much easier doing faculty fourth-year reviews and T\&P reviews within one department only, not with other departments. It's just problematic. Faculty are not familiar with this. One department may say yes; another department may say no. In a similar case, several years ago, we lost a very productive faculty doing what we call inter-/transdisciplinary research in the community to another university during the $\mathrm{T} \& \mathrm{P}$ review year. 
A newly hired faculty member in an applied social science field sharing her concerns, stated:

My dean [hired by a previous provost] does not want me to engage in international activities, nor does she understand what the transdisciplinary approach means. She said it is just too complex to understand and do it. The dean said I may not be fully supported by other senior faulty when I go through T\&P because our college's mission is serving the needs of the urban community. That is one of the key expectations to get full support from other faulty when I go through T\&P. The Dean said we have to work with the local partners for teaching and research, but I like the various funding programs the office [OITA] has, very impressive! I am very glad that I have accepted the position to join the faculty. I remember what the provost said during my job interview and know the provost wants us to engage in international endeavors with inter-/transdisciplinary matters. I am sure when we have new permanent dean hired by the current provost, the dynamic may and should change in my college and department. It seems happening lately. May I ask your office [OITA] to pay for my travel expenses for an invitation from a former colleague to make a presentation in Italy? In fact his area is economics, sociology, and psychology coupled with education; thus interaction with him in the field will be definitely be transdisciplinary in a transnational and transcultural context. Ha! I've got it now. And besides, I've never been to Italy!

This urban institution, which is the only research public university located in a large, well-known, metropolitan, international city, is in the process of a major transformation in order to become more responsive to the contemporary changes and needs of the life and future of the next generation. On one hand, infusing transdisciplinary internationalization into all aspects of academic affairs is one of the critical aspects of the strategic mission and profile of the university as well as its future. On the other hand, transdisciplinary internationalization is viewed as a "contradicting emphasis" by a good number of respectable and seriously dedicated faculty, staff, and administrators, who were hired by previous regimes with a different historical orientation. Mission driven visionary administrative leadership is one thing; transformative institutional culture change is another: Cultural change has been the most critical challenge in the strategic engineering of academic affairs at this urban public higher education institution.

\section{Pragmatic Approaches Toward Transdisciplinary Transformation in Higher Education Institutions}

At this point, based on what I have experienced so far, the following are pragmatic suggestions I would like to share with colleagues who may be responsible for facilitating the strategic engineering of academic affairs for transdisciplinary foci:

- Cross-disciplinary/joint faculty position articulation

- Cross-disciplinary/joint faculty search committee formation

- Cross-disciplinary faculty socialization for research

- Congruent tenure and promotion expectations (outside the monodisciplinary frame) [a new paradigm]

- Cross-departmental curriculum articulation and real-life problem solving-based research and learning experience at both the undergraduate and graduate levels (building for future faculty cross-disciplinary/transdisciplinary capacity)

- Both formal and informal curriculum for students' cross-border/integrative research experience

- Make sure you have a [trans]visionary leader at the head of academic affairs for the institution.

- Pay equal and balanced attention to strengthening both basic sciences [mono-disciplinary fields] and applied sciences.

- Provide both visible (explicit) and invisible (implicit) "public" spaces in the campus culture for faculty, students, and community members in conjunction with transdisciplinary teaching, 
research, and service. In tenure-system institutions, outreach by well-established, scholarly senior faculty outreach to other departments and their experimental discipline-borderless involvement with junior faculty and students may be important elements for the new way of thinking and doing.

- Establish an incentive mechanism-even if it is small in scale-that encourages faculty members to explore teaching and research initiatives with colleagues in other disciplines.

\section{Conclusion}

Transdisciplinarity is a means to increasing intellectual potential and awareness inside and outside typical disciplinary knowledge without a border, ultimately inspiring effective engagement in, with, to, and for the human community for the public good. Thus, transdisciplinary approach is a democratic epistemology and action. In comparison with various other disciplinarities (monodisciplinarity, Interdisciplinarity, multidisciplinary), transdisciplinarity denotes different academic disciplines working together without a "border," with practitioners and nonacademic ordinary community people (including industry, business, public administration, nongovernmental organizations, etc.) to understand real-life issues and phenomena and to collectively solve problems. As a result of globalization, technological innovation and complex social issues that risk the humanity, much of the problems we face today require transdisciplinary knowledge and collective engagement that is both transnational and transcultural. For that reason, some universities have created degree programs or specific strategic initiatives to build transdisciplinary capacity via academic units, centers or institutes (see examples in McGregor, \& Volckmann, [31]).

The transdisciplinary approach is a new form of shared research, shared learning, shared teaching, and shared problem solving for a shared social responsibility involving diverse sectors of the public and academia in order to meet the complex challenges of human society and its sustainability; it is democratic and ecologically sound (Hyun, [4]; Hyun, in press [32]). If we consider the history and evolution of higher education since the $15^{\text {th }}$ century, the transdisciplinary phenomenon is a cultural artifact of $21^{\text {st }}$ century higher education. Within the parameters of the university, curriculum is the center of reasoning, the artifact of the university. If curriculum is the center of reasoning in the university-What is curriculum? What does the curriculum do to individuals and human society? Why is an infusion of transdisciplinary curriculum and research into academic affairs an inevitable consideration now? Is university curriculum a condition or capacity of academic affairs, representing collective epistemology, geopolitical agenda, or politically engineered sociocultural and socioeconomical intention to prepare the next generation for various forms of engagement that may lead to socially responsive and humanistically sound action for sustainable human community?

Since World War II, the global population, crop production, and energy consumption have all increased dramatically. In addition to these physical entities, the total amount of human knowledge has multiplied exponentially in equally dramatic fashionmass production, mass consumption, mass disposal, mass mobility, mass environmental impact, megaurbanization, mega-complex public health problems, and the tremendous educational disparity between the rich and the poor. Nowadays, one scientist often does not understand what is going on in his or her neighbor's laboratory. They cannot even communicate with one another: same topic of research but in different languages that are specific only to one's own disciplinary thinking. This phenomenon of compartmentalization poses the greatest obstacle to the initiation of transdisciplinary ways of knowing. When we confront a real-life issue that demands resolution, we need to combine or integrate different disciplines to understand and solve the issue along with educating students in this mode for societal sustainability. The contemporary phenomenon of transdisciplinary curriculum discourse in higher education is inevitably and paradoxically influenced by industry-driven globalization; thus, it could be a reactive cultural artifact. It is, however, also a socially responsive transformative movement that deserves our collective attention for this generation in human endeavor. And that attention is overdue.

A perpetual and historical hindrance, however, causes faculty and administrators to avoid transdisciplinary pondering and thus miss a lived collective experience for change. Such avoidance is deeply rooted in traditional academic departmentalization: Departmental specialization has been emphasized (e.g., Wilshire, [33]) as part of the academic capacity 
of the modern university, where junior faculty members are advised to remain "pure," not "polluted" by the perspectives of other disciplines, and to reject inter- and transdisciplinary engagements. Consequently, borderless transdisciplinary collaboration among faculty members from various disciplines in pursuit of a real life-based inquiry was not under deliberate consideration. Still and all,

"The world has problems, but universities have departments" (Brewer, 1999)

"The right package is always imperfect but is the best deal you can actually implement" (Bolman \& Gallos, 2011)

And so we move forward!

\section{References}

[1] Brewer, G. D., 1999. The Challenges of Interdisciplinarity. Policy Sciences, 32, pp. 327-337.

[2] U. S. Department of Education (2006). The Test of Leadership: Charting the Future of U. S. Higher Education. A eport of commission appointed by Secretary of Education Margaret Spellings. Washington, DC: Author.

[3] Hyun, E., 2009. A study of US Academic Deans' Involvement in College Students' Academic Success. International Studies in Educational Administration. 37(2), pp. 89-110.

[4] Hyun, E., 2011. Transdisciplinary Higher Education Curriculum Transformation: A Complicated Cultural Artifact. Research in Higher Education Journal, 11, pp. 1-19. http://www.aabri.com/manuscripts/11753.pdf, accessed: November 28, 2012.

[5] Darbellay, F., Cockell, M., Billotte, J., \& Waldvogel, F. (Eds.)., 2008. A vision of Transdisciplinarity: Laying Foundations for a World Knowledge Dialogue. Boca Raton, FL: Taylor \& Francis Group.

[6] Hammer, M., \& Söderqvist, T., 2001. Enhancing Transdisciplinary Dialogue in Curricula Development. Ecological Economics, 38, pp. 1-5.

[7] Hadorn, G. H., Bradley, D., Pohl, C., Rist, S., \& Wisemann, R., 2006. Implications of Transdisciplinarity for Sustainability Research. Ecological Economics, 60, pp. 119-128.
[8] Jantsch, R., 1972. Toward Interdisciplinarity and Transdisciplinarity in Education and Innovation. In Centre for Educational Research and Innovation (CERI) (Eds.), Interdisciplinarity: Problems of Teaching and Research in Universities (pp. 97-212). Nice, France: OCED.

[9] Kaufman, D., Moss, D., \& Osborn, T. (Eds.)., 2003. Beyond the boundaries: A transdisciplinary approach to learning and teaching. Praeger: Westport, CT.

[10] Kessel, F., \& Rosenfield, P., 2008. Toward transdisciplinary research: Historical and contemporary perspectives. American Journal of Preventive Medicine, 35(2S), pp. 225-234.

[11] Klein, J. T., 2004. Prospects for transdisciplinarity. Futures, 26, pp. 515-526.

[12] Klein, J., Grossenbacher-Mansuy, W., Häberli, R., Bill, A., Scholz, R., \& Welti, M. (Eds)., 2001. Transdisciplinarity: Joint problem solving among science, technology, and society: An effective way for managing complexity. Basel, Switzerland: Birkhäuser.

[13] Lawrence, R. J., 2004. Housing and health: From interdisciplinary principles to transdisciplinary research and practice. Futures, 36, pp. 487-502.

[14] Kötter, R., \& Balsiger, P. W., 1999. Interdisciplinarity and transdisciplinarity: A constant challenge to the sciences. Issues in Integrative Studies, 17, pp. 87-120.

[15] Max-Neef, M. (2005). Commentary: Foundation of transdisciplinarity. Ecological Economics, 53, pp. $5-16$.

[16] Max-Neef, M. (2005). Commentary: Foundation of transdisciplinarity. Ecological Economics, 53, pp. $5-16$.

[17] Mroczkowski, T., 2012. The new players in life science innovation: Best practices in R\&D from round the world. Upper Saddle River, NJ: FT Press.

[18] Nicolescu, B., 1996. La transdisciplinarité,manifeste [Manifesto of transdisciplinarity]. Paris, France: Le Rocher.

[19] Nicolescu, B., 1997. Project CIRET-UNESCO: Evolution trandisciplinarie de I'Université. Bulletin interactif du CIRTE 9/10.

[20] Nicolescu. B., 2002. Manifesto of transdisciplinarity (K.-C. Voss, Trans.). New York, NY: SUNY Press.

[21] Nicolescu, B., 2007. Transdisciplinarity and the unity of knowledge: Beyond the science and religion dialogue. Retrieved from 
http://www.metanexus.net/magazine/tabid/68/id /10013/Default.aspx, accessed: April 13, 2010.

[22] Nicolescu, B. (Ed.)., 2008. Transdisciplinarity: Theory and practice. Cresskill, NJ: Hampton Press.

[23] Piaget, J., 1970. L'épistémologie des relations interdisciplinaires. In L'interdisciplinarité: Problémes d'ensseignement et de recherché dans les universities. Proceedings of a workshop. Nice, France.

[24] Pohl, C., 2005. Transdisciplinary collaboration in environmental research. Futures, 37, pp. 1159-1178.

[25] Ramadier, T., 2004. Transdisciplinarity and its Challenges: The Case of Urban Studies. Futures, 36, pp. 423-439.

[26] Wickson, F., Carew, A., \& Russell, A., 2006. Transdisciplinary Research: Characteristics, quandaries, and quality. Futures, 38, pp. 1046-1059.

[27] Seymour, D., 1988. Developing Academic Programs: The Climate for Innovation. ASHE-ERIC Higher Education Report, No. 3.Washington, DC: Association for the Study of Higher Education.

[28] CIRET: International Center for Transdisciplinary Research., 1997. Retrieved from http://basarab.nicolescu.perso.sfr.fr/ciret/ index_en.php

[29] Nicolescu, B., 1994. The transdisciplinary Evolution of Learning. International Center for Transdisciplinary Research (CIRET). Retrieved from http://www.learndev.org/dl/nicolescu_f.pdf, accessed: November 28, 2012.

[30] Bolman, L. \& Gallos, J., 2011. Reframing Academic Leadership. San Francisco, CA: Jossy-Bass.

[31] McGregor, S., \& Volckmann, R. (2011). Transversity: Transdisciplinary Approaches in Higher Education. Tucson, AZ: Integral Publishers.

[32] Hyun, E. (in press). Taking a Transdisciplinary Approach to the Life Sciences. In H. Stolte, E. Hyun, \& R. Paslack (Eds.), Advances in the Life Sciences: Transdisciplinary Interfaces Uniting Universities, Industries, and Governmental Organizations. New York, NY: Peter Lang.

[33] Wilshire, B., 1990. The Moral Collapse of the University: Professionalism, Purity, and Alienation. New York, NY: SUNY Press.

\section{About the Author}

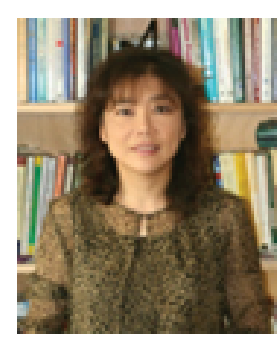

Eunsook Hyun, Ph.D., is Professor of curriculum studies and Associate Provost at the University of Massachusetts, Boston, USA. Prior to the current position, she served as Department Chair of Curriculum \& Instruction at UMass Boston and Program Director for various graduate and undergraduate programs in the College of Education at Kent State University, Ohio. She earned the Ph.D. in curriculum and instruction from the Penn State University, University Park, Pennsylvania, USA. Prof. Hyun is an established scholar and experienced administrator in higher education. Through her scholarship, Prof. Hyun has widely published in many areas, including curriculum theorizing, transdisciplinary higher education curriculum, developmentally and culturally appropriate practice (DCAP), early childhood education, teacher education, critical pedagogy, gender studies, bilingual education, theory of teacher reflectivity and multiple/multiethnic perspective-taking, inquiry-oriented reflective supervision, technology and young children, environmental education, academic deans' involvement and accountability in college students' academic success, the internationalization of higher education institutions, and minority faculty recruitment and retention. Her books include Teachable Moments: Re-Conceptualizing Curricula Understandings: Studies in the Postmodern Theory of Education (2006), Making Sense of Developmentally and Culturally Appropriate Practice (DCAP) in Early Childhood Education (1998), Transformative Teaching and Curriculum Practice in Higher Education: Transdisciplinary Approach (in progress), and Advances in the Life Sciences: Transdisciplinary Interfaces Uniting Universities, Industries, and Governmental Organizations (in press).

Copyright (c) 2012 by the author. This is an open access article distributed under the Creative Commons Attribution License (https://creativecommons.org/licenses/by/4.0/), which permits unrestricted use, distribution, and reproduction in any medium, provided the original work is properly cited. 